\title{
Os choques percepcionais do falhado processo de descolonização do Timor (1974-1975)
}

The Perception Shocks of Timor's Failed Decolonization Process (1974-1975)

\author{
Pedro Emanuel Mendes*
}

\section{RESUMo}

Este artigo realiza uma análise das razões, contextos e atores que conduziram a um processo de descolonização falhado no Timor-Leste em 1974-1975. Contextualiza os ambientes políticos e ideacionais em jogo dos atores-chave do processo de descolonização do Timor, com destaque para o processo negocial entre Portugal e a Indonésia e para os desenvolvimentos do processo político local entre os atores timorenses. Apresenta uma análise multinível do processo de descolonização do Timor, interligando os contextos de Portugal, Indonésia, Timor e o contexto da estrutura internacional. Parte de uma visão construtivista e agencial e sublinha os fatores identitários e sócio-cognitivos do processo negocial. Seu principal argumento é que, tão importante como os interesses materiais em jogo, as diferentes percepções e imagens culturais dos atores resultaram em choques percepcionais que minaram o processo, precipitaram crises e originaram o fim da via negocial.

Palavras-chave: Portugal; Indonésia; Timor; Política Externa; Percepções.

\section{Abstract}

This article analyses the reasons, contexts, and actors that led to a failed decolonization process in East Timor in 1974-1975. The article contextualizes the political and ideational environments at play for key actors in the Timor decolonization process, with a focus on the negotiation process between Portugal and Indonesia and the developments in the local political process among Timorese actors. The article presents a multilevel analysis of Timor's decolonization process, linking the contexts of Portugal, Indonesia, Timor and the context of the international structure. It starts from a constructivist and agential vision and underlines the identity and socio-cognitive factors of the negotiation process. Its main argument is that, as important as the material interests at stake, the actors' different perceptions and cultural images resulted in perceptional clashes that undermined the process, precipitated crises, and gave rise to the end of the negotiation path.

Keywords: Portugal; Indonesia; Timor; Foreign Policy; Perceptions.

\footnotetext{
* Universidade NOVA de Lisboa (UNL), Lisboa, Portugal e Universidade de Coimbra (UC) pemanuelmendes@gmail.com <https://orcid.org/0000-0002-6321-8344>
} 


\section{INTRODUÇÃO}

Este artigo apresenta uma análise relativa aos diferentes interesses e percepções em jogo na questão timorense durante o início do seu turbulento processo de descolonização. Realiza uma contextualização histórica dos primeiros contatos diplomáticos entre Portugal e a Indonésia sobre o Timor, sublinhando as diferentes percepções destes atores diplomáticos, bem como dos atores timorenses locais face ao caminho a seguir após o fim do império português no Timor.

O seu principal objetivo é o de iluminar as contradições, ambiguidades e diferentes percepções que marcaram os primeiros episódios históricos do complexo processo multinível - nacional, local, regional e internacional - associado ao fim do regime imperial português, bem como o seu processo de transição e a sua interligação com a explicação das origens e das causas da descolonização falha no Timor.

Com base no cruzamento de fontes primárias e secundárias, desenvolve-se uma narrativa analítica sobre os principais acontecimentos nacionais, locais, regionais e internacionais que marcaram o desenrolar do processo negocial que originou um desfecho inédito para a ex-colônia portuguesa no sudeste asiático. $\mathrm{O}$ artigo desenvolve-se ao longo de seis secções, identificando os principais contextos materiais e ideacionais dos atores-chave no processo e os principais encontros negociais entre Portugal e a Indonésia. Interligadamente, são demonstradas as diferentes visões identitárias em jogo, bem como a dinâmica do gradual aumento de tensões e conflitos de interesses, que exponenciaram o que denominamos choques percepcionais entre os vários atores políticos e influenciaram o descarrilamento do processo negocial.

Ao contrário das abordagens tradicionais, excessivamente racionalistas e estruturalistas, apresenta-se neste artigo uma visão construtivista e agencial, sublinhando-se as diferentes visões e percepções sobre os interesses em jogo nas origens do processo falhado de descolonização do Timor em 19741975. Para além da demonstração das dificuldades do processo de descolonização, devido aos diferentes interesses estruturais, nacionais e locais, o seu principal argumento é que, ao longo de uma negociação internacional, é necessário ter-se em conta a relação entre os choques percepcionais e o dinamismo e a imprevisibilidade dos jogos e crises políticas envolvidos na situação. 


\section{O AMBIENTE POLÍTICO DA TRANSIÇÃO PORTUGUESA: EFEITOS DE CONTÁGIO E A PERCEPÇÃO INDONÉSIA}

O golpe de libertação militar ocorrido em abril de 1974 inicia em Portugal um período de transição democrática altamente instável, sobretudo entre 1974-1976, a fase pré-constitucional. Portugal teve de lidar com seis governos provisórios, dois presidentes da República, várias tentativas de golpe e contragolpe militar e, simultaneamente, conseguir uma solução política para as três frentes de guerra na África. De uma forma interdependente, Portugal desenvolve um processo interno de transição democrática e um processo externo de descolonização e normalização internacional (Mendes, 2004).

Em contraste com os territórios africanos, nos quais ocorriam conflitos militares e políticos com movimentos de libertação, no Timor não existiam movimentações políticas e militares que pusessem em questionamento o poder da Administração Colonial portuguesa. O Timor era, não só a colônia mais esquecida, como a que menos preocupação dava à metrópole. Comparativamente, até o dia 25 de abril, existia no Governo do Timor uma situação confortável (RGT, 1981, p. 19).

$\mathrm{Na}$ abertura solene da Assembleia Legislativa do Timor, do dia 30 de abril de 1974, o governador do território, tenente-coronel Alves Aldeia, afirma: "nesta hora de tremendas responsabilidades na governação, as cisões não aproveitam, as ideologias terão de ser superadas pela vontade de continuar Portugal" (RGT, 1981, p. 20). Ora, o que iria acontecer nos meses seguintes seria bem o contrário: as cisões dos timorenses, as influências contraditórias das ideologias e uma vontade de continuar Portugal facilmente superável.

No início de maio de 1974, Alves Aldeia solicita à Junta de Salvação Nacional (JSN), em Lisboa, informações sobre as coordenadas da nova política para o território. A resposta que obteve foi a de passar a agir de acordo com os princípios do programa do Movimento das Forças Armadas (MFA) e, atendendo às condições locais, evitar a degradação das relações com a Indonésia (RGT, 1981).

Contudo, à medida que os acontecimentos se desenrolam, é visível a crescente incapacidade das autoridades portuguesas de controlar a situação. Por um lado, porque os recursos humanos e políticos locais são escassos e não estão preparados para o fim da tranquilidade. Por outro, porque não foram 
mobilizados novos meios para que Portugal tivesse capacidade de impor uma autoridade estabilizadora no Timor (Mendes, 2012a).

Claro que o ambiente político e ideacional vivido nesta altura em Portugal tornava muito problemático o exercício tradicional da autoridade militar. Devido a um "fator de ordem psicanalítica" (Reis, 1989, p. 116), os militares portugueses não estavam motivados a permanecer nas colônias. Este fator determinou a socialização ideológica e política do slogan: "nem mais um soldado para as colónias". Isto significa que é necessário ter-se consciência das dificuldades existentes sobre a possibilidade de um reforço do contingente militar português. Todavia, contrafactualmente, este reforço poderia ter feito toda a diferença. ${ }^{1}$ Contudo, a força dos fatos diz-nos que, naquela altura, os militares queriam ser desmobilizados (RCAEPDT, 1981, p. 38), e não mobilizados para um território asiático desconhecido, situado a 16.000 quilômetros de distância de Portugal. No entanto, isso não foi possível. O possível foi, no mês de maio, a chegada a Timor de uma delegação do MFA para estudar in loco a situação.

De imediato, em 5 de maio, anunciou-se a total liberdade dos timorenses constituírem partidos políticos. Em seguida, no dia 13 de maio, o governador Alves Aldeia formou a Comissão para a Autodeterminação do Timor, a qual incentivou a constituição de associações civis (Krieger, 1997, pp. 25-29). No dia 11, fundou-se a União Democrática Timorense (UDT), que defendia uma federação com Portugal e a independência a longo prazo. No dia 20, foi fundada a Associação Social Democrata Timorense (ASDT), que se transformou, a 11 de setembro 1974, na Frente Revolucionária do Timor-Leste Independente (FRETILIN). Este partido defendia a independência total e imediata do país (CAVR, 2005, pp. 16-18). Ramos-Horta, secretário político da ASDT, visitou Jacarta em 17 de junho para obter uma garantia de apoio da Indonésia à independência. Na altura, o ministro dos Negócios Estrangeiros indonésio, Adam Malik, respondeu que "a independência é um direito de cada nação [...] e a Indonésia respeitará Timor Independente” (Carrascalão, 2002, p. 205).

Apesar do discurso da Indonésia ir na direção do respeito pela legalidade e pelas normas internacionais, a Indonésia, desde a década de 1960, tinha definido uma política de incorporação do Timor Português. ${ }^{2}$ Todavia - e este é o nó górdio da questão -, Adam Malik percebe imediatamente a ASDT/FRETILIN como comunista. Em sua opinião, a FRETILIN era controlada pelos comunistas e, para um regime que se tinha legitimado contra o comunismo, 
eliminando violentamente o Partido Comunista Indonésio (PKK) (Mendes, 2016), não era possível admitir-se um Timor comunista. Neste sentido, Adam Malik afirma que: "if we recognize FRETILIN, it is possible that our name will rise in the world. But this will mean that we have betrayed our nation. ${ }^{3}$ (Suryadinata, 1996, p. 56).

No final de maio, dão-se alterações nas lideranças portuguesas no território. O major Arnão Metello ${ }^{4}$, chefe do Estado-maior do comando militar local, é nomeado delegado do MFA no Timor e, no dia 1 de julho, o governador Alves Aldeia é substituído pelo coronel Nívio Herdade.

Em Lisboa, no dia 27 de junho, acontece o corolário do Programa do MFA, assumindo-se a ideia-chave da normalização da política externa portuguesa. Assim, é decretada e promulgada a Lei n. 7/74. Esta lei, de caráter constitucional, sublinha a solução política e não militar dos conflitos coloniais e enfatiza a normalização e a consequente conformidade com as normas internacionais. Portugal assume, "de acordo com a Carta das Nações Unidas, o reconhecimento do direito dos povos à autodeterminação" (Diário do Governo, 1974).

No mesmo dia, no Timor é fundada a Associação Popular Democrática Timorense (APODETI), que defende a integração do Timor à Indonésia. No dia 9 de agosto, Arnaldo Araújo, da APODETI, visita Jacarta para conversações com o governo indonésio. Alegadamente, os seus objetivos relacionam-se ao auxílio indonésio para a elaboração do programa de seu partido - o que não deixa de ser elucidativo sobre quem, desde o início, conduz este movimento. Em setembro, começam as primeiras confrontações entre a APODETI e a FRETILIN.

\section{A visita a Lisboa do General Ali Moertopo}

No dia 14 de outubro, chega a Lisboa uma comitiva indonésia chefiada pelo general Ali Moertopo, representante pessoal do presidente Suharto. O objetivo da visita oficial é expresso numa missiva enviada ao primeiro-ministro Vasco Gonçalves. Nesta carta, datada de 5 de outubro, o presidente indonésio explica que envia Ali Moertopo a Lisboa por duas razões principais: 
to obtain first-hand information concerning your Government's policies with regard to the process of decolonization of the territories under Portuguese administration. On the other hand, through Lieutenant General Ali Moertopo I wish to convey to you my views and the views of the Government of Indonesia on the above mentioned subject, especially with regards to Portuguese Timor ${ }^{5}$ (apud Carrascalão, 2002, p. 327, grifos nossos).

A visita da delegação indonésia não foi fácil. Refletindo o ambiente político da época, existiu alguma descoordenação relativamente aos contatos com as entidades políticas e governamentais. Isto influenciou a visão indonésia sobre as dificuldades portuguesas em definir uma política clara para o Timor. Com efeito, neste momento tudo indica que Portugal não tinha uma estratégia política capaz de afirmar os seus interesses numa lógica de independência, ou até de eventual contradição com os interesses da Indonésia. Os complexos processos de luta política interna e os urgentes processos de descolonização na África faziam do Timor um assunto menos relevante.

Nesta altura, Portugal aparenta ter uma política simplista e casuística, mas sensível às posições da Indonésia. Contudo, não existia uma estratégia clara. A política para o Timor era variável de acordo com os atores e com as marés políticas. Era uma navegação à vista, sem um rumo claro. Isto mesmo constatou o general indonésio. Ali Moertopo teve encontros com o Presidente da República, Costa Gomes, com o primeiro-ministro, Vasco Gonçalves, e com o ministro dos Negócios Estrangeiros, Mário Soares. Estes atores tinham diferentes visões do mundo e consequentes imagens relativamente aos projetos sobre a política interna e externa de Portugal (Mendes, 2012b). Deste modo, a delegação Indonésia percebe divergências nos decisores portugueses e consolida a percepção de que Portugal não está em condições de pensar num Timor independente, reforçando a sua ideia de integrar o Timor-Leste.

Ademais, não se pode menosprezar o impacto da reunião com Costa Gomes, que terá defendido que o Timor era um caso semelhante a Goa. Portanto, da mesma forma natural que a grande Índia absorveu a pequena Goa, seria natural que a grande Indonésia absorvesse o pequeno Timor português (Cruzeiro 1998). Esta visão, que reflete o trauma que a posição de resistência militar - ordenada por Salazar em Goa - provocou em Portugal, contribuiu para a percepção indonésia de que, no final, Portugal tinha uma posição conciliatória relativa à tese da integração do Timor na Indonésia. 
É plausível que Moertopo tenha percebido que a posição portuguesa, embora não muito clara, não era incompatível com a posição da integração do Timor à Indonésia. Os agentes indonésios captaram positivamente os seguintes critérios da posição de Portugal: primeiro, o país não encarava a independência do território como viável e realista; segundo, não negava os especiais interesses indonésios na região; terceiro, afirmava uma política anticolonialista (RCAEPDT, 1981, pp. 44-54; Pires, 1994, p. 49).

Ao contrário da política portuguesa, por parte da Indonésia existiam ideias claras para o Timor. A estratégia indonésia consistia em apresentar uma agenda aos governantes portugueses, que passava pelos seguintes pontos principais: primeiro, a Indonésia estava bastante preocupada com a instabilidade no Timor; segundo, o Timor tinha graves problemas, do ponto de vista do desenvolvimento econômico e social, que o governo indonésio estava preparado para ajudar a resolver; terceiro, o povo timorense tinha origem comum no povo indonésio; quarto, a independência do Timor era inviável, apenas restando duas alternativas possíveis: a ligação a Portugal ou a ligação à Indonésia (Mendes, 2012a).

Na verdade, a delegação indonésia parece ter já uma alternativa escolhida: a de ligação à Indonésia, tanto mais que tinha sido essa a conclusão alcançada em reunião com a outra potência regional, a Austrália. Antes da visita a Portugal, tinham já ocorrido, na capital indonésia, em setembro, reuniões de alto nível entre funcionários dos ministérios dos Negócios Estrangeiros indonésio e australiano.

Mais: existiu um encontro entre o presidente Suharto e o primeiro-ministro Whitlam, no qual se chegou a um consenso de estabilidade regional relativamente ao Timor. A Austrália manifestou o seu acordo à eventual integração do Timor na Indonésia, pois esta seria "a solução natural e inevitável" (RGT, 1981, p. 33). Contudo, a Austrália não podia demonstrar publicamente uma política unívoca e tentou navegar pelos pingos da chuva. Por um lado, o governo australiano defendia a natural incorporação do Timor na Indonésia; por outro, defendia que esta incorporação fosse feita por meios diplomáticos e pacíficos. No final do dia, as intenções benignas do governo australiano foram ultrapassadas pela eficácia dos interesses econômicos e pela política de força da Indonésia, e a Austrália resignou-se à situação da invasão e da posterior anexação do Timor. 
Tudo indica que o grande objetivo da viagem diplomática de Moertopo a Lisboa era regressar a Jacarta e confirmar ao presidente Suharto que Portugal também não seria um obstáculo à ligação natural com a Indonésia. Dos seus contatos com as entidades portuguesas, Moertopo reteve uma visão compreensiva face à posição indonésia. Esta sua percepção foi reforçada quando recebeu indicações claras de que Portugal não desejava continuar a governar o território do Timor e que não via a independência como uma opção viável (Australia and the Indonesian Incorporation..., 2000, pp. 124-25).

Evidentemente isto não significava que Portugal tivesse garantido a Moertopo que era favorável a uma anexação do Timor por parte da Indonésia. Todavia, a percepção Indonésia era a de ler, nas declarações portuguesas, por exclusão de hipóteses, um óbvio apoio à visão da estratégia indonésia. A existência de uma preconcepção cognitiva para o problema da parte indonésia, juntamente com a pouca clareza das posições portuguesas, fez com que a delegação indonésia partisse de Lisboa convencida de que a sua posição não seria contrariada por Portugal.

\section{A visita do Ministro Coordenação \\ Interterritorial, Almeida Santos, ao Timor}

O Ministro da Coordenação Interterritorial (MCI), Almeida Santos, visita o Timor em outubro. A situação era já eminentemente explosiva, com a APODETI e a FRETILIN em posições opostas e conflito latente. A UDT, a única que defendia a ligação a Portugal, vê a sua visão reforçada com a presença e as palavras do ministro português.

Almeida Santos discursa em Díli e afirma que não é pró nem contra a independência total e imediata, mas salienta que "Timor está longe da independência económica”, e alerta para "os perigos do neocolonialismo económico” (RGT, 1981, p. 22). Em sua opinião, o “Timor deve optar entre ilusórias perspetivas de fartura imediata e definitivas possibilidades de independência [...]. E aí é que Portugal [...] pode surgir, digamo-lo sem empenho, mas sem receio, como o natural aliado de Timor" (RGT, 1981, p. 22).

Numa linguagem diplomaticamente conveniente, o ministro português afirma igualmente que não será pró ou contra "qualquer sorte de conexão política com a República da Indonésia”. Todavia, salienta que isso se trataria 
da contradição do "fenómeno da descolonização [...]. Pois que se trata de autonomizar, não há de dar total satisfação a uma colónia a simples mudança de colonizador" (RGT, 1981, p. 22). Apesar de reafirmar o princípio da autodeterminação popular, sublinhando que qualquer solução só poderia resultar desse ponto de partida, Almeida Santos não esconde a sua preferência sobre o Timor continuar ligado a Portugal. Com efeito, as suas afirmações são claras relativamente ao desejo sobre o resultado da consulta popular aos timorenses: "a grande maioria da população de Timor deseja continuar ligada a Portugal. Se esse desejo vier a encontrar confirmação no resultado da consulta a que será submetida, nada poderá ser mais honroso para os portugueses e para o seu governo" (RGT, 1981, p. 22). Neste caso, afirma o ministro, "não faltarão a Timor, nem o suporte financeiro compatível com as nossas possibilidades, nem o suporte técnico ao nosso alcance, nem o apoio humano, esse inesgotável" (RGT, 1981, p. 23).

Ainda que tranquilizadora para a UDT, e, sobretudo, apaziguadora do ambiente de tensão hostil que se vivia em Díli, a visita de Almeida Santos não foi, mais uma vez, tão clarificadora, para o Timor e para Portugal, como a visita da delegação da Indonésia a Lisboa. Desta resultaria a convicção de que Portugal, desde que respeitados os princípios básicos de autodeterminação livre do povo timorense, não se oporia à integração do Timor à Indonésia. Da visita do ministro português a Díli continuam a resultar mais interrogações do que convicções políticas inequívocas.

O discurso de Almeida Santos, embora positivo, esbarrava nas várias visões existentes, em Portugal e no Timor, sobre os caminhos da política portuguesa face ao Timor. Mesmo a posição de Almeida Santos teve variações que possibilitavam várias interpretações (Gorjão, 2002). Isto não significa que Almeida Santos não tivesse uma visão relativamente clara no que concernia à descolonização do Timor. Relativamente às três opções básicas que estavam em discussão - independência total e imediata; ligação a Portugal e autodeterminação progressiva e integração à Indonésia -, a sua opção pela ligação a Portugal tinha sido já enunciada em entrevista ao jornal Expresso. O problema fundamental é que, durante a fase de transição pré-constitucional em Portugal, o que pensava um ministro não era sinônimo do pensamento do governo, ou de uma política externa totalmente coerente por parte do Estado. Existiam várias e diferentes opções relativamente à descolonização, à política externa 
em geral, e sobre o que deveria ser Portugal e o seu posicionamento internacional (Mendes, 2004). O Timor não foi imune ao quadro de permanente instabilidade interna que se viveu em Portugal, designadamente, ao confronto político entre projetos e visões de mundo muitas vezes contraditórios (Correia, 1999). Nesta fase, a posição portuguesa sobre o Timor variava de acordo com a personalidade política com quem se contatasse (Australia and the Indonesian Incorporation..., 2000, p. 119), o que foi decisivo na percepção indonésia sobre as intenções da política externa portuguesa para o Timor.

Parece claro, porém, que a posição de Almeida Santos é a de deixar cair a opção de independência total e imediata, permitindo-se um confronto entre as outras duas hipóteses, por meio do qual, num obrigatório processo de autodeterminação, a sua opção de ligação a Portugal vencesse a opção de ligação à Indonésia. É esta estratégia que resulta, quer de seu discurso em Díli, em outubro, quer de seu discurso na ONU, no início de dezembro. Aqui, Almeida Santos reafirma que o Timor só poderá ter uma de duas soluções: manter-se ligado a Portugal ou ligar-se a Indonésia. E que, no que dizia respeito a Portugal, continuava a existir a determinação de se prosseguir o processo de descolonização progressiva, garantindo que o Timor teria uma assembleia constituinte no prazo de seis meses (RGT, 1981, p. 39).

\section{As tentativas DE CONTROLAR O PROCESSO POR PARTE DE PORTUGAL: REAÇÕES E POSIÇÕES DOS ATORES NO TIMOR}

Ainda em dezembro, chegava a Díli o enviado especial do MCI, Valadas Preto, com um projeto de estatuto orgânico, semelhante ao proposto para os territórios sem guerra, S. Tomé e Príncipe e Cabo Verde, para ser apresentado e discutido com os partidos políticos timorenses. O objetivo português era o de conseguir tê-lo pronto até finais de janeiro de 1975. Mais uma vez, o desenrolar dos acontecimentos não permitiu que tal objetivo se cumprisse. A FRETILIN não o aceitou. Já a UDT aceitava o estatuto e propunha a consulta referendária para julho, e a APODETI não admitia a discussão do estatuto por achá-lo desnecessário, defendendo o referendo para outubro (RGT, 1981, p. 23).

Em Díli desde 18 de novembro, o novo governador, Lemos Pires, propõe, em dezembro, a instituição de um Conselho de Governo com funções consultivas, no qual estariam presentes todos os partidos. Esta ideia ia ao encontro do 
pensamento de Almeida Santos e estava em consonância com os seus objetivos de iniciar um processo político que possibilitasse uma plataforma de acordo para se proceder a um referendo de autodeterminação. Todavia, o desentendimento entre os partidos políticos timorenses foi notório e não foi possível ativar-se com sucesso esta parceria entre o governo português local e os partidos políticos, que já manifestavam interesses claramente contraditórios.

A APODETI desejava a rápida integração com a Indonésia, no intuito de promover os interesses políticos e econômicos que daí resultariam para o seu grupo. A UDT e a FRETILIN eram claramente anti-indonésias. Todavia, para além desta comunhão nacionalista, os seus interesses não eram coincidentes. Basicamente, a posição da UDT era a de manter o domínio de alguns postos-chave da administração pública e os interesses políticos e econômicos daí decorrentes. Assim, a UDT defendia a ligação com Portugal, pois achava que esta seria a melhor maneira de preservar estes interesses. Contrariamente, a FRETILIN defendia o saneamento da atual elite dirigente e administrativa no Timor e a sua substituição por uma nova elite timorense sem ligações políticas com a antiga administração colonial, por isso, defendia uma independência que significaria a ruptura com os interesses ligados à antiga administração colonial e à Indonésia.

Claro que, a esta visão consequencialista dos interesses, teremos que agregar uma visão mais construtivista, no sentido de compreender quais as ideias e identidades que estão na base desses interesses (Mendes, 2018). Assim, podemos dizer que a APODETI defendia uma ideia pan-javanesa (Mendes, 2016; 2017) e achava que, em última análise, o Timor-Leste deveria fazer parte de uma grande Indonésia (RGT, 1981, p. 34). Por sua vez, a UDT defendia a ideia da integração do Timor numa comunidade de língua portuguesa, assumindo a visão benigna de um Portugal luso-tropical, multirracial e pluricontinental (Mendes, 2020). Ao contrário da APODETI, a UDT achava que o Timor-Leste tinha uma maior ligação identitária com Portugal do que com o Sudeste Asiático. Finalmente, a ASDT, que se transforma em FRETILIN, defendia uma ideia anticolonialista com fortes influências das correntes marxistas, muito em voga em vários países recém-descolonizados e em vias de desenvolvimento, com destaque para a sua ligação à FRELIMO de Moçambique. A FRETILIN era claramente o partido mais ideológico. A sua identidade política relevava mais os princípios revolucionários e anticoloniais da esquerda inter- 
nacionalista do que qualquer ligação privilegiada a Portugal ou à Indonésia (RGT, 1981, pp. 28-31).

Em todos os processos políticos de transição, a agregação e a desagregação de interesses são especialmente complexos, voláteis e determinados por permanentes movimentos reconstitutivos. Isto significa que, embora fosse evidente a diversidade de interesses e ideias dos partidos timorenses, é importante compreender-se esta diversidade dentro de um contexto dinâmico. Estes interesses e estas ideias originais marcam o posicionamento dos partidos timorenses. Contudo, não deixa de ser menos correto dizer que mesmo nestes partidos existiam diversas correntes, umas mais radicais, outras mais moderadas. Isto significa que, ao longo do tempo, e consoante o predomínio de cada uma dessas correntes, o discurso e a ação política destes grupos políticos vão se adaptando e alterando de acordo com as circunstâncias, que mudam radicalmente no ano de 1975.

No terreno, a Indonésia começa a preparar a sua estratégia. Primeiro, através da hábil condução política de seu cônsul em Díli, Tomodok, depois, através da propaganda na rádio com base na capital do Timor oriental, Kupang. Em terceiro, a Indonésia fará tudo para apoiar diretamente a APODETI e permitir a anexação do Timor-Leste.

O próprio governador do Timor oriental, El Tari, escreve ao governador do Timor português uma carta, datada de 13 de janeiro, na qual afirma que, em sua opinião, o governador português "tem de ajudar a fazer a união com a Indonésia [...] e deve empurrar os partidos para um único objetivo, o da união com a Indonésia” (RGT, 1981, pp. 73-75).

Em resposta às movimentações crescentes da Indonésia, via APODETI, os partidos UDT e FRETILIN formam uma coligação de interesses negativa, uma frente pró-independência capaz de combater as forças pró-integração. Esta plataforma de entendimento é anunciada em cerimónia pública a 21 de janeiro (RGT, 1981, pp. 77-78). A tensão no Timor é crescente. O mês de fevereiro inicia-se com boatos constantes sobre uma iminente invasão militar indonésia. No dia 24, uma rádio australiana afirma que a Indonésia prepara um ataque militar a Díli e Bacau nas próximas semanas. No dia 27, a agência de notícias indonésia ANTARA noticia que a situação no Timor português evolui no sentido de os comunistas da FRETILIN tomarem o poder, e que esta fora autorizada a adquirir armas. No dia anterior, chega a Díli o chefe dos 
Negócios Políticos da embaixada australiana em Jacarta, ali permanecendo até 5 de março.

Cada vez mais pressionados pelos acontecimentos - leia-se, pela pressão pró-Indonésia -, os partidos anti-Indonésia, UDT/FRETILIN, começam a querer negociar com Portugal. São insistentes os pedidos de contato com o governo em Lisboa, mas na capital portuguesa existem outras preocupações. Na verdade, passada a fase heroica da Revolução dos Cravos, estão latentes os processos de aceleração da luta entre o projeto revolucionário e o projeto democrático (Mendes, 2004).

Mesmo sem respostas de Lisboa, em Díli, a 18 de fevereiro, a coligação UDT/FRETILIN elabora uma proposta concreta para discutir com o governo de Portugal. Esta proposta assenta-se nos seguintes princípios básicos: 1) na manutenção do sistema de governo existente por mais dois anos, com um conselho alargado; 2) num período seguinte de três anos, com um alto-comissário e um governo de transição com membros dos partidos, mantendo-se o conselho de governo; 3 ) num período seguinte de mais dois anos nesse sistema, e na eleição de uma assembleia constituinte para decidir, finalmente, o futuro do território. Relativamente às relações internacionais e à Indonésia em particular, defendiam-se os seguintes princípios: 1) política de não-alinhamento; 2) pacto de não-agressão; 3) cooperação na manutenção da paz; 4) não-intervenção (RGT, 1981, pp. 48-49).

Mais uma vez, não existiu, por parte de Lisboa, qualquer resposta ao projeto. Todavia, Portugal sabia que era fundamental tentar diminuir a pressão indonésia, daí resultando o encontro de Londres, no dia 9 de março. Este será o segundo encontro entre o general Moertopo e o ministro Almeida Santos, depois de se terem encontrado em Lisboa em outubro de 1974.

\section{Encontros e desencontros entre Portugal, Indonésia} E OS TIMORENSES: DE LONDRES A MACAU

Para além do objetivo imediato de retomar a comunicação entre governos, e, logo, de baixar a tensão, o encontro de Londres foi importante, pois serviu para reformatar a percepção indonésia relativamente ao encontro de Lisboa. Neste primeiro encontro, como vimos, a percepção indonésia foi de que Portugal iria acompanhar o objetivo indonésio de anexar o Timor. 
No segundo encontro ${ }^{6}$, Portugal tornou mais explícita à Indonésia a posição de não obstaculizar nenhuma opção à partida, incluindo, para grande surpresa do general Moertopo, a possibilidade da independência do Timor. Moertopo terá insistido que, em Lisboa, lhe teriam assegurado que Portugal iria apoiar a posição indonésia. A delegação portuguesa, por sua vez, insistiu que Portugal não iria fazer nada para apoiar, tampouco para dificultar a posição indonésia. O seu principal interesse era o de possibilitar que o povo do Timor pudesse livremente escolher o seu futuro. Portugal assumiu que estava, sobretudo, interessado em iniciar um processo político local que acautelasse os princípios de descolonização e de autodeterminação consagrados pela ONU, princípios que eram a trave mestra da política externa do Portugal livre (Soares, 1974).

A proposta portuguesa consistia numa solução que defendia um período de transição gradual de cinco a oito anos, que culminaria com um referendo de autodeterminação. Portugal fez questão de sublinhar que a Indonésia não era irrelevante nesta solução, e que a manteria informada da sua evolução nomeadamente, das conversações com os partidos políticos agendadas para maio. Todavia, Portugal insistiu que, se não fosse possível obter-se um acordo para se desenvolver este processo, não lhe restaria outra opção senão internacionalizar a questão junto à ONU. A delegação indonésia discordou claramente desta possibilidade (RCAEPDT, p. 77).

Em Lisboa, passados dois dias, rebenta o 11 de Março, acentuando-se a percepção indonésia de que os comunistas estavam tomando o poder em Lisboa e de que isso se refletiria no Timor, particularmente com o apoio à FRETILIN. Aumenta a pressão indonésia para se utilizar a opção militar. No dia 14 de março, a embaixada de Portugal em Jacarta comunicava que

segundo fontes de confiança Suharto, foi nas últimas semanas solicitado e mesmo pressionado pelos chefes de segurança e militares para autorizar a intervenção militar em Timor português. O presidente optou pela negativa, chegando mesmo a ameaçar demitir quem persistisse numa linha de ação militar (RGT, 1981, p. 50).

Isto demonstra que, de um ponto de vista militar, a operação de invasão estava já equacionada; o que não existia ainda era a oportunidade política. Terá sido isso que, nesta fase, fez com que Suharto não desse ouvidos aos seus 
militares mais duros. O presidente Suharto terá pensado que a situação, de um ponto de vista interno e internacional, ainda não estava suficientemente madura para uma intervenção militar.

Todavia, as campanhas de propaganda na rádio e na imprensa indonésia, sobre o perigo do comunismo no Timor, e as suas consequências para a instabilidade e a insegurança na Indonésia e na região, intensificam-se. Por outro lado, mais uma vez ecoavam o processo revolucionário em Portugal e as implicações do 11 de Março para o avanço comunista em Lisboa, bem como os seus veículos de transmissão no Timor.

Também para Timor, o 11 de Março significou um corte importante no processo político que se tentava impor, especificamente nas conversações com os partidos políticos timorenses. O governador Lemos Pires, que se encontrava em Lisboa para resolver problemas do Timor, esclarece-nos a situação: "Os acontecimentos do 11 de Março vieram impedir o efeito de diversas diligências que o governador tentara em Lisboa, onde praticamente deixou de existir governo" (RGT, 1981, p. 51).

Os meses seguintes, maio e junho, são centrados na tentativa de se fazer avançar o processo político no Timor, iniciando-se conversações com os partidos sobre o processo e a calendarização da descolonização. A primeira ronda de reuniões ocorre no dia 7 de maio, com os dirigentes da coligação FRETILIN/UDT. Nelas, Portugal propõe uma agenda com as premissas básicas sobre o programa de descolonização (RGT, 1981, pp. 157-158). No dia 9 de maio ocorre a segunda ronda de reuniões com a APODETI. Importa sublinhar aqui que a APODETI rejeita a premissa básica de direito à independência, alegando que a constituição da Indonésia não prevê a integração de países independentes. Também rejeita a participação num governo de transição e os calendários propostos para os atos eleitorais.

As reuniões não foram fáceis, com o agravante de terem existido divergências mesmo da parte portuguesa, entre a Comissão de Descolonização do Timor e a Comissão Nacional de Descolonização (CND), quanto ao desenvolvimento dos calendários (RGT, 1981, p. 163). Finalmente, a CND envia a Díli o major Vítor Alves, embaixador itinerante que já havia acompanhado a situação do Timor em Londres. O major chega a Díli no dia 15 de maio e, quando regressa a Lisboa, leva consigo o acordo da coligação UDT/FRETILIN e da APODETI sobre as premissas básicas para a realização de uma cimeira da 
qual participariam Portugal e os partidos timorenses, a ter lugar em Macau no dia 15 de junho.

Tudo parecia bem encaminhado, até que acontece o que mais se temia: o fim da coligação UDT/FRETILIN, ou seja, a moderação é ultrapassada pela radicalização de posições. A ala mais radical da FRETILIN começa a inviabilizar a sua presença na cimeira de Macau. Apesar das insistências portuguesas, a FRETILIN não comparece e apenas dois partidos marcam a sua presença em Macau. Na prática, isto inviabilizou a celebração de um acordo geral no qual ficassem finalmente estabelecidas as linhas definidoras do processo de descolonização do Timor.

Ainda assim, de acordo com o combinado em Londres, a delegação portuguesa - composta por Vítor Alves, Almeida Santos, o secretário de Estado dos Negócios Estrangeiros, Jorge Campinos e dois representantes do governo do Timor - encontra-se com uma delegação indonésia em Hong Kong, no dia 25 de junho. É apreciado o projeto de lei constitucional que estaria em discussão com os partidos em Macau no dia seguinte (Mendes, 2012 a).

Em Macau, as negociações com a APODETI e UDT decorrem sem grandes dificuldades, e são poucas as alterações introduzidas ao projeto que anteriormente estivera em discussão em Díli. O resultado é um acordo quanto ao novo estatuto orgânico do Timor e a definição do processo e do calendário da descolonização (Krieger, 1997, p. 37).

Finalmente, ocorre, em Hong Kong, um novo encontro entre Portugal e a Indonésia, prestando-se, ali, esclarecimentos sobre as decisões e os resultados da cimeira, constatando-se uma relativa compreensão por parte da Indonésia. A preparação e o resultado da cimeira de Macau evidenciam a vontade de Portugal de contribuir para uma solução descolonizadora que permitisse uma livre escolha do futuro do Timor. Portugal não adotou uma atitude defensiva e demonstrou disponibilidade para negociar todas as opções, até mesmo a integração à Indonésia, desde que fossem cumpridos os requisitos de um processo de autodeterminação conforme as normas internacionais. Contudo, a cimeira de Macau demonstra também as limitações e a incapacidade de Portugal controlar, no terreno, a radicalização dos partidos políticos, que se tornará irreversível com o fim da coligação UDT/FRETILIN. O acordo de Macau foi patrocinado por Portugal. Definiram-se as etapas sobre um período inicial transitório que proporcionasse condições de possibilidade de construção do 
Estado, bem como o reconhecimento de que o estatuto final do território teria de ser realizado livremente pelo povo timorense, através de um referendo democrático e supervisionado internacionalmente, de acordo com as normas da ONU (Santos 1995; 2006).

Contudo, o acordo no papel não acompanhou a luta política no terreno. O fim da coligação UDT/FRETILIN foi determinado pela ascensão da ala radical da FRETILIN, que começa a atuar através da infiltração nos meios militares e a recorrer a ações violentas. Este comportamento introduz um nível de insegurança e de intranquilidade na sociedade timorense, arrasta reações dos outros partidos e eleva a escalada de insegurança no território. Isto vai ser politicamente aproveitado pela Indonésia.

Em Lisboa, no dia 11 de julho, o Presidente Costa Gomes promulga o diploma constitucional decretado pelo Conselho da Revolução, no qual se afirma:

O Estado Português reafirma o direito do povo de Timor à autodeterminação, com todas as suas consequências, incluindo a aceitação da sua independência, e a derrogação da parte correspondente do artigo $10^{\circ}$ da Constituição Política de 1933, nos precisos termos da lei constitucional n. ${ }^{\circ} 7 / 74$, de 27 de julho, de acordo as resoluções pertinentes da Organização das Nações Unidas, e na escrupulosa salvaguarda do princípio do respeito pela vontade do povo de Timor (Diário do Governo, 1975).

Este diploma põe em marcha o processo de descolonização do Timor e define o seu novo estatuto orgânico. Os pontos básicos eram os seguintes: 1) o futuro político do Timor seria definido por uma Assembleia Popular que resultaria de uma eleição direta, secreta e universal, a qual ocorreria no terceiro domingo de outubro de 1975;2) num prazo de 100 dias, seriam constituídos órgãos transitórios de governo do Timor português, que exerceriam funções até se eleger a Assembleia Popular do Timor. Após esta eleição, através de um ato solene entre o seu Presidente e o Presidente da República portuguesa, Portugal terminaria a sua soberania no território.

Novamente, o desencadear dos acontecimentos veio contrariar o programa estabelecido. Em primeiro lugar, em Lisboa, a crise política entre o IV e os $\mathrm{V}$ governos provisórios aumenta a instabilidade e a incerteza sobre a questão clássica: quem governa? O que, mais uma vez, significa que as crises de política interna em Portugal fazem atrasar o processo no Timor. 
Na véspera do governador do Timor sair de Díli em direção a Lisboa, para ser empossado como alto-comissário - um dos pressupostos da lei 7/75 -, ele recebe o seguinte telegrama: "Sexa Presidente da República considera que Vexa deve aguardar instruções antes de deslocar-se Lisboa” (RGT, 1981, p. 227). Resultado: no Timor, não existe Alto-comissário; o processo de instituição da lei 7/75 não avança, ficando tudo em suspenso.

Do ponto de vista do governo do Timor, isto significou um período de grande indefinição política, administrativa e legal no território, com graves consequências para a autoridade portuguesa. Por outro lado, do ponto de vista dos partidos políticos timorenses, significou uma percepção da incapacidade de Portugal para conseguir encontrar uma solução eficaz à descolonização do Timor. Terá sido esta percepção, aliada às declarações do presidente da Indonésia, em meados de julho, a defender que o futuro do Timor passaria pela integração na Indonésia, que terá levado a UDT - outrora tão confiante e próxima da autoridade de Portugal - a visitar Jacarta em 25 de julho, e a fazer uma viragem política de 360 graus. Esta visita é justificada pela UDT, pela necessidade de indagar a Indonésia relativamente à sua aceitação sobre a opção de independência do Timor. Os fatos posteriores, as manifestações, as greves e, finalmente, o golpe, parecem comprovar a possibilidade de, no decurso desta visita, a Indonésia ter conseguido influenciar a UDT, no sentido de esta perpetrar um movimento militar com o objetivo de eliminar os comunistas da FRETILIN. ${ }^{7}$

É plausível que a Indonésia tenha confrontado a UDT com uma opção de soma nula, ou seja, que tenha feito ver à UDT que era impossível a FRETILIN continuar no Timor, e que o apoio da Indonésia a uma possível solução de independência do Timor dependeria da sua eliminação. A verdade é que, após dois dias do regresso da delegação da UDT de Jacarta, realizam-se em Díli greves e manifestações organizadas pela UDT, exigindo uma clarificação do governo português local, liderado pelo coronel Lemos Pires, e a expulsão do território de dois majores - alegadamente revolucionários e conspiradores ao serviço da FRETILIN (RGT, 1981, p. 229; CAVR, 2005, p. 46).

\section{O AUMENTO DA TENSÃO E O DESCARRILAMENTO DO PROCESSO POLÍTICO}


Na noite de 10 para 11 de agosto, a UDT põe em marcha a sua tentativa de golpe. ${ }^{8}$ Claro que existem versões diferentes sobre os acontecimentos de 11 de agosto (CAVR, 2005, pp. 44-49; Carrascalão, 2002, pp. 32-39). Para a UDT, tratou-se de um movimento de reação perante a crise generalizada e a degradação das condições de segurança que representou a ascensão da FRETILIN, permitida pelo governador Lemos Pires e ocorrida com o apoio dos oficiais revolucionários do MFA. Para a FRETILIN, o golpe começou a desenhar-se depois da cimeira de Macau, com a conivência de Lemos Pires, numa atitude persecutória em razão da sua ausência nesta cimeira. A FRETILIN cateteriza o golpe da UDT como "uma ofensiva reacionária e imperialista” (Carrascalão, 2002, p. 35).

Nos dias seguintes, a situação tornou-se extremamente complexa e, com a reação da FRETILIN o ambiente político rapidamente se deteriora. A partir de 21 de agosto, "Díli passou a viver em ambiente de guerra civil com as forças militares divididas pelos dois partidos" (RGT, 198, p. 237).

É o fim do statu quo ante alguma estabilidade, e o início da grande incerteza e das turbulências política e militar no território. A partir daqui, o governo português do Timor perde completamente o controle da situação. O auxílio do governo central de Portugal é escasso e claramente insuficiente, face à gravidade da situação. Perante a condição de colapso da autoridade portuguesa, que se reflete na incapacidade de juntar as partes e impor um cessar-fogo, Portugal começa a tentar o auxílio da "ONU e países limítrofes para negociação com movimentos políticos em Timor, a fim de conseguir-se solução política honrosa" (RGT, 1981, p. 267).

O ministro Almeida Santos parte para Nova Iorque, onde é recebido pelo secretário-geral da ONU e pelo presidente do Comité dos 24 . Estes se mostram compreensivos da gravidade da situação e prontificam-se a influenciar a Austrália e a Indonésia para uma ajuda humanitária ao Timor. A proposta portuguesa era a de se criar imediatamente um comitê de Bons Ofícios, constituído por Portugal, Indonésia, Austrália e, no mínimo, mais um país da região (RGT, 1981, p. 277), que possibilitasse "uma força de intervenção multilateral pacífica" (Santos, 2006, p. 14).

Todavia, no terreno, a situação urge e a ajuda não chega nem de Portugal, nem da ONU, tampouco das potências da região. O que chega é a "ordem para sair da capital” (RGT, 1981, p. 277), do Presidente da República ao gover- 
nador do Timor, o que acontece no dia 28 de agosto. Neste dia, é concretizada a transferência da autoridade portuguesa. O governo e o comando militar português do Timor em Díli viajam para a pequena ilha de Ataúro.

A partir deste momento, a autoridade portuguesa deixa de ter uma presença física no centro político e social do território, Díli. Perde-se o elo simbólico de poder do governo português no Timor. Sem capacidade operacional, militar e política, resta a Portugal manter uma presença da soberania portuguesa em Ataúro, e tentar as diligências diplomáticas. ${ }^{9}$

Depois da ONU, a delegação portuguesa chefiada por Almeida Santos dirige-se a Jacarta e a Camberra para tentar negociar uma solução. Em Jacarta, a Indonésia propõe a Almeida Santos um "Draft Memorandum of Understanding", com seis pontos, no qual, embora reconhecendo que Portugal é a única autoridade no Timor, avança a ideia de se constituir uma autoridade conjunta composta por Indonésia, Portugal, Austrália e Malásia (RGT, 1981, p. 323). Esta autoridade só se constituiria após o pedido português dirigido à Indonésia, para que esta se disponibilizasse a enviar uma task force para restabelecer a paz e a ordem no Timor. Esta task force estaria sob o comando indonésio, no entanto, isto apenas se daria após o estabelecimento da autoridade conjunta.

Portugal não concorda com o memorando e apresenta uma resposta à Indonésia, expondo as suas várias reservas à proposta (RGT, 1981, pp. 323324). Basicamente, Almeida Santos rebate a aparente contradição entre o reconhecimento de Portugal como única autoridade legítima e o estabelecimento de uma autoridade conjunta, e afirma, peremptoriamente, que "o governo português não está em posição de solicitar uma intervenção militar unilateral da Indonésia” (RGT, 1981, p. 324).

Não se conseguiu chegar a um entendimento. Entretanto, a FRETILIN passa a controlar grande parte do território e exige negociações diretas com Portugal para a descolonização e a autodeterminação. Almeida Santos insiste na negociação de um processo político que envolva os três partidos e, perante as desconfianças indonésias, chega mesmo a entregar um documento ao MNE da Indonésia no qual nega um acordo bilateral entre Portugal e a FRETILIN, reafirmando a vontade de "recondução do processo de descolonização do território a uma plataforma política que respeite a vontade genuína do povo de Timor" (RGT, 1981, p. 297).

Os meses de setembro e outubro são de impasse. As negociações entre os 
partidos não avançam e a posição portuguesa está também condicionada pela existência de militares portugueses prisioneiros. $\mathrm{Na}$ Indonésia, os decisores percebem o impasse como negativo e insustentável. Não param de pensar nas consequências possíveis das declarações oscilantes das elites portuguesas, ou seja, na hipótese levantada pelo ministro português, Almeida Santos, de que Portugal poderia entregar o poder aos timorenses, o que, na prática, significava entregar o poder à FRETILIN. Esta solução era impensável para os decisores indonésios.

No dia 5 de setembro, o Presidente Suharto e o general Moerdani reuniram-se e analisaram sete opções possíveis para a resolução do problema do Timor. Essas opções iam de um convite à Indonésia, por parte de Portugal, para a intervenção direta, até o envolvimento das Nações Unidas, da qual a Indonésia participava. Todavia, Suharto, em resultado de sua percepção sobre a situação, descartou todas as opções, exceto o plano das Operações Especiais, que descreveu como a "via clássica". A partir deste momento, inicia-se o plano segundo o qual as forças armadas indonésias forneceriam "voluntários" bem armados, os quais apoiariam a UDT e outras forças timorenses anti-FRETILIN, numa aposta clara para impedir que a FRETILIN se apoderasse do Timor (Australia and the Indonesian Incorporation..., 2000, pp. 391-392).

Com esta decisão, Suharto selou a derrota do processo de descolonização do Timor, abrindo a porta para a solução anexadora militar, que nunca resolveu a questão da autodeterminação timorense.

\section{Conclusão}

Como vimos, para além dos diferentes interesses em jogo - de Portugal, da Indonésia e dos timorenses -, o processo negocial de descolonização do Timor falha em razão dos choques percepcionais que se vão desenvolvendo entre os seus atores-chave. Isto não significa a negação das clássicas causas estruturais da questão do Timor: a guerra-fria e a estabilização regional, o anticomunismo do regime autoritário indonésio, os interesses materiais do mar do Timor e os jogos diplomáticos internacionais de paralisação da ONU; às quais importa acrescentarem-se as questões internas relativas à transição portuguesa, que se ramificam e contagiam o governo e os atores do Timor-Leste, as divisões entre os atores timorenses, bem como a cultura política 
autoritária e militarista da Indonésia. Todas estas causas estiveram presentes e desempenharam o seu papel. Todavia, como argumentamos, interrelacionadamente às causas estruturais, internacionais, nacionais e locais, importa sublinharmos que o processo negocial da descolonização descarrilou devido a fatores agenciais, ou seja, às diferentes percepções que, em momentos críticos, complexificaram o processo negocial de descolonização.

Como este artigo demonstra, para além dos interesses divergentes das partes, o que dá complexidade a um processo negocial - minando a sua racionalidade e a sua eficiência negocial - são os choques percepcionais entre os atores. As diferentes percepções sobre o mesmo problema, ou ainda, a convicção de uma percepção errada sobre quais são os interesses em jogo, minam a negociação e geram crises. Outro fator decisivo na explicação do processo falhado do Timor é relativo à política interna e ao tipo de liderança e de regime político dos atores-chave do processo. Assim, tanto o incapacitante ambiente político que se vive em Portugal quanto a cultura política militarista e anticomunista da Indonésia deram complexidade ao desenrolar do processo e exponenciaram os choques percepcionais.

Estes choques percepcionais decorrem, simultaneamente, da lógica racional de ponderação deliberativa do jogo de maximização de interesses da política internacional, mas também da lógica identitária dos atores que formatam as suas imagens culturais (Mendes, 2018) e determinam as suas percepções sobre os acontecimentos das situações (Mendes, 2020). Embora interligados, é possível se identificarem dois tipos de choques percepcionais na questão do Timor. $\mathrm{O}$ primeiro é um choque percepcional constitutivo, que resulta das divergentes identidades e imagens culturais dos atores em jogo. O segundo é um choque percepcional situacional, que resulta das tradicionais misperceptions (Jervis, 2017) que ocorrem na política internacional e nos seus processos diplomáticos.

Assim, em primeiro lugar, ocorreram choques percepcionais decorrentes das diferentes identidades de Portugal e da Indonésia. Numa lógica identitária de normalização pós-imperial e democrática, pontuada por um certo neo-lusotropicalismo esquerdizante, Portugal defende o princípio de descolonização de acordo com as normas internacionais da ONU, que postulam, especialmente, a participação e a decisão dos timorenses na sua autodeterminação. Por seu lado, numa lógica identitária anti-imperialista, autoritária e pan-javanesa, a Indonésia defende que o Timor-Leste deve fazer parte dela, independentemen- 
te dos processos de autodeterminação dos timorenses. Para complexificar esta divergência identitária, os próprios timorenses assumiram identidades e papéis diferenciados entre si e face à Indonésia e a Portugal.

Em segundo lugar, existiram percepções diferentes sobre os acontecimentos e as próprias comunicações e afirmações dos vários intervenientes políticos no processo negocial, que minaram a negociação e aumentaram o risco de conflito.

Por fim, este artigo contribui para se demonstrar que, em processos de descolonização e transição política, é necessário desenvolver-se uma importante aptidão de inclusão dos atores locais. Como se comprova, nestas situações é decisivo não se deixar o processo descarrilar para uma excessiva polarização política que estimule o desenvolvimento de visões antagônicas, as quais levam os interesses das partes a serem percebidos como inconciliáveis.

\section{REFERÊNCIAS}

DIÁRIO DO GOVERNO. I série, 27 jul. 1974.

DIÁRIO DO GOVERNO. I série, 17 jun. 1975.

AUSTRALIA AND THE INDONESIAN INCORPORATION of Portuguese Timor, 1974-1976; DFAT (Department of Foreign Affairs and Trade, Carlton: Melbourne UP), 2000.

ROSTOW, Walt. Memo from Walt Rostow to Averell Harriman; NSA (National Security Archive, USA). Indonesia and Portuguese Timor, February 5, 1963.

CAVR (Relatório da Comissão de Acolhimento, Verdade e Reconciliação de Timor-Leste). Timor-Leste, 2005.

CARRASCALÃO, Maria Ângela. Timor: os Anos da Resistência. Queluz, Portugal: Mensagem, 2002.

FEIJÓ, Rui. Metelo, António Carlos de Magalhães Arnão. In: REIS, António; REZOLA, Maria Inácia; SANTOS, Paula Borges (Eds.). Dicionário de história de Portugal: o 25 de Abril. Vol. 5. Porto: Figueirinhas, 2017.

FERNANDES, Moisés Silva. A preponderância dos factores exógenos na rejeição do plano português de descolonização para Timor-Leste, 1974-1975. Negócios Estrangeiros, v. 10, pp. 90-171, 2007.

GORJÃO, Paulo. O fim de um ciclo: as políticas externas da Austrália e de Portugal em relação a Timor Leste. Análise Social, vol. XXXVII, n. 164, pp. 911-936, 2002.

JERVIS, Robert. Perception and Misperception in International Politics. New Edition. New Jersey: Princeton University Press, 2017.

KRIEGER, Heike (Ed.). East Timor and the International Community: Basic Documents. New York: Cambridge University Press, 1997. 
MENDES, Pedro Emanuel. A dimensão internacional da transição democrática em Portugal: a influência da Europa. População e Sociedade, Porto, n. 11, pp. 171-192, 2004.

MENDES, Pedro Emanuel. O Poder e as ideias na política externa do Portugal democrático: o caso de Timor. Tese (Doutorado em Relações Internacionais) - Faculdade de Ciências Sociais e Humanas, Universidade Nova de Lisboa, 2012a.

MENDES, Pedro Emanuel. Portugal e a Europa: Factores de Afastamento e Aproximação da Política Externa Portuguesa (1970-1978). Porto: CEPESE, 2012b.

MENDES, Pedro Emanuel. Identidade e poder na política externa da Indonésia: de Sukarno a Suharto. Relações Internacionais, n. 52, pp. 67-82, 2016.

MENDES, Pedro Emanuel. O poder e as ideias na política externa da Indonésia democrática: ser ou não ser um ator global? Relações Internacionais, n. 55, pp. 71-98, 2017.

MENDES, Pedro Emanuel. Identidade, ideias e normas na construção dos interesses em política externa: o caso português. Análise Social, vol. 227, pp. 458-487, 2018.

MENDES, Pedro Emanuel. Percepções e imagens na política externa do Estado Novo português: a importância do triângulo identitário. Dados, vol. 63, n. 3, pp. 1-35, 2020.

PEREIRA, Zélia. Da chegada do 25 de Abril a Timor: a controversa ação do major Arnao Metello. Ler História, n. 77, pp. 181-203, 2020.

PIRES, Mário Lemos. Descolonização de Timor: missão impossível? Lisboa: Dom Quixote, 1994.

RAMOS-HORTA, José. Funu: The Unfinished Saga of East Timor. Lawrenceville: The Red Sea Press, 1987.

RCAEPDT (II Relatório da Comissão de Análise e Esclarecimento do Processo de Descolonização de Timor). Presidência do Conselho de Ministros, Lisboa, 1981.

RGT (I Relatório do Governo de Timor, 1974-1975). Presidência do Conselho de Ministros, Lisboa, 1981.

REIS, António. O Partido Socialista no poder e na oposição: da dialéctica com o projecto nacional-militar à dialéctica com o eanismo. In: COELHO, Mário Baptista (Coord.); SOARES, Mário (Pref.). Portugal: o Sistema Político e Constitucional 19741987. Lisboa: Instituto de Ciências Sociais da Universidade de Lisboa, 1989. pp. 111-146.

SANTOS, António de Almeida. Quase Memórias. Lisboa: Casa das Letras, 2006.

SURYADINATA, Leo. Indonesia's Foreign Policy under Suharto: Aspiring to International Leadership. Singapore: Times Academic Press, 1996. 


\section{NOTAS}

${ }^{1}$ Portugal, que chegou a ter cerca de 3000 militares no Timor em 1974, reduziu estas tropas para cerca de 200 militares em meados de 1975. De acordo com Ramos-Horta, "esta redução do número de soldados foi o erro mais prejudicial cometido pelos portugueses em 1974" (Ramos-Horta, 1987, p. 48).

${ }^{2}$ Esta política de incorporação e as suas consequências são discutidas pelos EUA já em 1963 (Rostow, 1963).

${ }^{3}$ Tradução nossa: "se reconhecermos a FRETILIN, é possível que o nosso nome se levante no mundo. Mas isto significará que traímos a nossa nação".

${ }^{4}$ Sobre a influência de Metello e as diferentes visões das autoridades portuguesas no Timor, ver Pereira (2020) e Feijó (2017).

${ }^{5}$ Tradução nossa: "para obter informações em primeira mão sobre as políticas do seu Governo em relação ao processo de descolonização dos territórios sob a administração portuguesa. Por outro lado, através do Tenente-General Ali Moertopo, desejo transmitir-lhe a minha opinião e a do Governo da Indonésia sobre o assunto acima mencionado, especialmente no que diz respeito ao Timor Português".

${ }^{6}$ A delegação portuguesa era formada pelo ministro da Coordenação Interterritorial, Almeida Santos, pelo ministro sem pasta Vítor Alves, pelo secretário de Estado dos Negócios Estrangeiros Jorge Campinos e pelo chefe do Gabinete dos Assuntos Políticos do Governo do Timor, major Francisco Mota. A delegação indonésia era liderada pelo general Ali Moertopo, pelos embaixadores da Indonésia no Reino Unido e na França e pelo capitão Suharto, dos serviços de informação, Bakin.

${ }^{7}$ Existiria mesmo uma lista dos "comunistas" a serem eliminados (RGT, 1981, p. 227).

8 Designada “operação Sakonar” (RGT, 1981, pp. 252-253). A UDT toma de assalto o quartel da PSP e captura as suas armas, cerca o palácio do governo e exige a expulsão dos elementos revolucionários da FRETILIN das Forças Armadas, bem como o estabelecimento de um governo de transição. Em reação, a FRETILIN ocupa o quartel-general e o governador Lemos Pires ordena aos oficiais metropolitanos a entrega do comando das unidades militares aos sargentos timorenses. Derrotadas pela FRETILIN, as forças da UDT recuam até a fronteira com o Timor oriental, onde, após aceitarem a integração do Timor à Indonésia, lhes é permitido atravessar a fronteira. As forças da UDT e da APODETI foram treinadas pela Indonésia, que os designa "partidários". As tropas indonésias e os Partidários conduziram operações militares secretas no Timor-Leste entre agosto e dezembro de 1975 (Mendes, 2012a).

${ }^{9}$ Sobre as diligências diplomáticas portuguesas neste período, ver Fernandes (2007).

Artigo submetido em 5 de outubro de 2020. Aprovado em 22 de abril de 2021. 